Article Type: Research Paper

\title{
Analisis Determinasi Pola Konsumsi Mahasiswa Universitas Muhammadiyah Yogyakarta
}

\author{
Retno Sugianti ${ }^{1}$ and Lilies Setiartiti ${ }^{1}$
}

\begin{abstract}
Abstrak: Penelitian ini bertujuan untuk menganalisis faktor-faktor apa saja yang menentukan pola konsumsi mahasiswa UMY. Pengumpulan data pada penelitian ini menggunakan kuesioner. Jumlah sampel yang digunakan sebanyak 100 responden, menggunakan teknik random sampling. Variabel bebas yang digunakan pada penelitian ini yaitu uang saku, gaya hidup, literasi ekonomi, dan dummy fakultas. Hasil dari penelitian menunjukkan bahwa variabel uang saku dan literasi ekonomi memilki pengaruh terhadap pola konsumsi mahasiswa UMY. Variabel gaya hidup dan dummy fakultas tidak memiliki pengaruh terhadap pola konsumsi mahasiswa UMY.

Kata Kunci: Pola Konsumsi; Uang Saku; Gaya Hidup; Literasi Ekonomi; Fakultas.
\end{abstract}

${ }^{1}$ Department of Economics,
Faculty of Economics and Business,
Universitas Muhammadiyah
Yogyakarta, Yogyakarta, Indonesia.

*KORESPONDENSI:

retno.sugiarti.2015@fe.umy.ac.id

\section{ARTIKEL INI TERSEDIA DI:}

http://journal.umy.ac.id/index.php/jerss

DOI: 10.18196/jerss.030209

SITASI:

Sugiarti, R., \& Setiartiti, L. (2020). Analisis Determinasi Pola Konsumsi Mahasiswa Universitas

Muhammadiyah Yogyakarta. Journal of Economics Research and Social Sciences, 4(1), 83-90.

\section{Pendahuluan}

Setiap masyarakat di dunia ini tidak akan terlepas dari kegiatan konsumsi barang dan jasa, di mana hal tersebut dilakukan untuk mendapatkan kepuasan dari penggunaan barang dan jasa tersebut. Konsumsi merupakan sebuah variabel yang penting dalam makroekonomi. Dornbusch, Fisher, dan Startz (2001), mereka menyatakan dalam bukunya bahwa konsumsi menempati lebih dari 60 persen permintaan agregat, lebih dari jika semua sektor lain digabungkan. Fluktuasi konsumsi secara proporsional lebih kecil dari fluktuasi PDB. Oleh karena itu, konsumsi merupakan bagian yang besar dan stabil dalam PDB.

Teori konsumsi Keynes mengatakan bahwa konsumsi yang dilakukan saat ini tergantung pada pendapatan yang siap dibelanjakan saat ini. Dengan demikian semakin besar pendapatan, semakin besar pula tingkat konsumsi. Arthur Smithies berpendapat bahwa keputusan konsumsi tergantung pada pendapatan absolut, yaitu pendapatan pada saat melakukan konsumsi dan pendapatan dari stok kekayaan. Dari dua teori ahli ekonomi tersebut dapat diketahui bahwa salah satu faktor konsumsi yaitu pendapatan.

Pola konsumsi masyarakat tentunya akan berbeda-beda setiap individu. Menurut Hanum (2017) pola konsumsi adalah gambaran alokasi dan komposisi atau bentuk konsumsi yang berlaku secara umum. Menurut Hanum (2017), pola konsumsi dapat dikenali berdasarkan alokasi penggunaannya. 


\section{Sugiarti \& Setiartiti}

Analisis Determinasi Pola Konsumsi Mahasiswa Universitas Muhammadiyah Yogyakarta

Menurut KKBI Mahasiswa adalah pelajar perguruan tinggi serta dalam struktur pendidikan Indonesia menduduki jenjang satuan pendidikan tertinggi diantara yang lainnya (Sianturi, 2018). Mahasiswa merupakan suatu golongan dari masyarakat tentunya melakukan kegiatan konsumsi juga dalam kesehariannya baik itu konsumsi barang maupun jasa. Pola konsumsi mahasiswa tentunya berbeda dengan masyarakat biasa. Biasanya kegiatan konsumsi mahasiswa hanya terbagi untuk kebutuhan kuliah, kebutuhan non-kuliah, dan konsumsi makanan sehari-hari.

Untuk melihat cakupan yang lebih jelas lagi, penulis memilih Universitas Muhammadiyah Yoyakarta (UMY) sebagai cakupan penelitian. UMY merupakan salah satu universitas yang ada di Provinsi DIY, tepatnya di Kabupaten Bantul. Universtas Muhammadiyah Yogyakarta memiliki beberapa fakultas yaitu: Fakultas Ekonomi dan Bisnis, Fakultas IImu Sosial dan IImu Politik, Fakultas Hukum, Fakultas Pendidikan Bahasa, Fakultas Kedokteran dan Ilmu Kesehatan, Fakultas Teknik, Fakultas Pertanian, dan Fakultas Agama Islam.

Mahasiswa Universitas Muhammadiyah Yogyakarta tentunya melakukan kegiatan konsumsi seperti mahasiswa lain pada umumnya. Pola konsumsi Mahasiswa Universitas Muhammadiyah Yogyakarta memiliki perbedaan setiap individunya. Secara umum pola konsusmsi mahasiwa terbagi kepada dua hal yaitu untuk konsumsi makanan dan konsumsi non-makanan. Berdasarkan wawancara kepada Mahasiswa UMY pengeluaran konsumsi terbesar setiap bulannya yang dilakukan Mahasiswa Universitas Muhammadiyah Yogyakarta yaitu untuk konsumsi makanan sehari-hari. Selain konsumsi makanan sehari-hari, pengeluaran konsumsi yang dilakukan Mahasiswa Universitas Muhammadiyah Yogyakarta yaitu untuk keperluan kuliah dan non-kuliah.

Konsumsi yang berbeda antar mahasiswa bisa dipengaruhi oleh beberapa faktor, salah satunya yaitu pendapatan. Hal ini sesuai dengan penelitian yang dilakukan oleh Nurlaila Hanum, dalam penelitiannya menyebutkan bahwa pendapatan berpengaruh secara positif terhadap tingkat konsumsi Mahasiswa Universitas Samudra (Hanum, 2017). Selain faktor pendapatan, bisa jadi perbedaan tingkat konsumsi juga dipengaruhi oleh pengetahuan ekonomi. Sesuai dengan penelitian Indrianawati dan Soesatyo, pada penelitiaanya dijelaskan bahwa pendapatan berpengaruh terhadap tingkat konsumsi Mahasiswa Pascasarjana Universitas Negeri Surabaya dan pengetahuan ekonomi berpengaruh secara negatif terhadap tingkat konsumsi Mahasiswa Pascasarjana Universitas Negeri Surabaya (Indrianawati \& Soesatyo, 2015).

Perkembangan zaman seperti sekarang membuat sebagian mahasiswa pun sering mengikuti gaya hidup negara-negara maju. Sebagian mahasiswa sering mengikuti trend yang sedang booming, seperti fashion dan makanan yang berasal dari luar negeri. Hal tersebut itu juga dapat berpengaruh terhadap tingkat konsumsi mahasiswa. Sesuai dengan penelitian Budanti, Indriayu, dan Sabandi dalam penelitiannya menyebutkan bahwa gaya hidup berpengaruh secara signifikan terhadap perilaku konsumsi Mahasiswa Program Studi Pendidikan Ekonomi FKIP UNS (Budanti dkk, 2017). 


\section{Tinjauan Pustaka}

Indrianawati dan Soesatyo (2015) menyimpulkan bahwa tingkat pendapatan berpegaruh secara siginifkan terhadap tingkat konsumsi Mahasiswa Universitas Negeri Surabaya. Damayanti (2017) menggunakan 100 responden dalam penelitiannya untuk melihat pola konsumsi mahasiswa UMY. Hasil penelitiannya menunjukkan bahwa uang saku dan jurusan berpengaruh secara signifikan terhadap pola konsumsi mahasiswa UMY, sedangkan jenis kelamin tidak berpengaruh. Penelitian selanjutnya yang terkait dilakukan oleh Lutfiah, Hadi, dan Rokhmani (2015). Penelitian ini menggunakan metode korelatif dan analisis regresi linier berganda. Jumlah responden penelitian ini yaitu 78 mahasiswa. Hasil dari penelitian menunjukkan bahwa kontrol diri dan uang saku berpengaruh positif terhadap pola konsumsi mahasiwa. Mahasiswa yang mempunyai uang saku tinggi cenderung memiliki kontrol diri yang rendah sehingga pola konsumsinya cenderung tidak rasional. Mahasiswa yang mempunyai uang saku sedang dan rendah cenderung memiliki kontrol diri yang tinggi sehingga pola konsumsinya cukup rasional.

Mufidah (2012) mengatakan bahwasannya perilaku pemanfaatan foodcourt di Tanjung Plaza oleh masyarakat Surabaya pada saat ini telah mengalami pergeseran pola hidup. Jika dulu foodcourt merupakan tempat makan saja, sekarang foodcourt sudah menjadi gaya hidup. Foodcourt menjadi identitas bagi beberapa kalangan tertentu. Menikmati makanan makanan cepat saji di foodcourt bukan lagi untuk memenuhi kebutuhan makan saja melainkan bagian dari gaya hidup.

Dalam penelitian Ahmed, Mughal, dan Zarzoso (2018), hasil penelitian mereka menunjukkan bahwa pengiriman uang asing menyebabkan perubahan konsumsi yang signifikan. Pengiriman uang tidak meningkatkan konsumsi barang dan rekreasi melainkan alokasi untuk pendidikan meningkat secara substansial. Pengiriman uang domestik pada rumah tangga pengeluarannya fokus untuk SDM yaitu kesehatan dan pendidikan. Penerima uang transfer internasional yang hidup di bawah 1 dolar per hari lebih banyak membelanjakannya untuk makanan dibandingkan dengan mereka yang bukan penerima, sedangkan anggaran untuk pendidikan dan kesehatan sama.

Penelitian selanjutnya yang dilakukan oleh Sri Mulyani (2015), Penelitian ini menggunakan analisis statistik deskriptif dan crosstabs. Hasil penelitiannya menunjukkan bahwa pengeluaran konsumsi mahasiswa baik itu perempuan atau lakilaki banyak dihabiskan untuk konsumsi non-makanan. Mahasiswa perempuan lebih besar pengeluarannya dari mahasiswa laki-laki, baik itu konsumsi makanan maupun non-makanan. Pengeluaran konsumsi non-makanan yang paling tinggi yaitu untuk konsumsi fashion sebesar 39,86\%, kedua untuk hiburan sebesar 22,36\%, ketiga untuk transportasi sebesar $18 \%$, keempat untuk komunikasi sebesar $11,90 \%$, terakhir untuk biaya penunjang kuliah sebesar 7,03\%. 


\section{Metode Penelitian}

Penelitian ini dilakukan untuk mengetahui pengaruh uang saku, gaya hidup, literasi ekonomi, dan dummy fakultas terhadap Pola Konsumsi Mahasiswa UMY. Obyek pada penelitian ini yaitu mahasiswa aktif S1 Universitas Muhammadiyah Yogyakarta. Jenis data yang digunakan pada penelitian yaitu data primer, yaitu data yang diambil secara langsung dari responden. Teknik pengumpalan data pada penelitian ini menggunakan kuesioner tertutup. Jumlah sampel yang digunakan pada penelitian ini sebesar 100 responden, yang ditentukan berdasarkan rumus slovin dengan nilai signifikansi $10 \%$.

Adapun variabel bebas yang digunakan pada penelitian ini yaitu variabel uang saku, gaya hidup, literasi ekonomi, dan dummy fakultas. Variabel terikat yaitu pola konsumsi mahasiswa UMY. Pada penelitian ini analisis yang digunakan yaitu analisis regresi linear berganda, uji hipotesis (uji F, uji T, dan koefisien determinasi), uji asumsi klasik, dan uji validitas serta uji reliabilitas.

\section{Hasil dan Pembahasan}

Untuk mendapatkan hasil yang terbaik, penulis melakukan beberapa pengujian sebagai berikut.

Tabel 1 Hasil Uji Validitas dan Realibilitas

\begin{tabular}{|c|c|c|c|c|c|c|}
\hline Item & R Hitung & R Tabel & Signifikansi & Keterangan & $\begin{array}{l}\text { Alpha } \\
\text { Croncbach }\end{array}$ & Keterangan \\
\hline U1 & 0,753 & \multirow[t]{20}{*}{0,361} & 0,000 & Valid & \multirow[t]{4}{*}{0,529} & \multirow{4}{*}{$\begin{array}{l}\text { Reliabilitas } \\
\text { Moderat }\end{array}$} \\
\hline U2 & 0,465 & & 0,010 & Valid & & \\
\hline U3 & 0,737 & & 0,000 & Valid & & \\
\hline U4 & 0,638 & & 0,000 & Valid & & \\
\hline G1 & 0,485 & & 0,007 & Valid & \multirow[t]{6}{*}{0,732} & \multirow{6}{*}{$\begin{array}{l}\text { Reliabilitas } \\
\text { Tinggi }\end{array}$} \\
\hline G2 & 0,657 & & 0,000 & Valid & & \\
\hline G3 & 0,732 & & 0,000 & Valid & & \\
\hline G4 & 0,597 & & 0,000 & Valid & & \\
\hline G5 & 0,819 & & 0,000 & Valid & & \\
\hline G6 & 0,666 & & 0,000 & Valid & & \\
\hline L1 & 0,808 & & 0,000 & Valid & \multirow[t]{5}{*}{0,758} & \multirow{5}{*}{$\begin{array}{l}\text { Reliabilitas } \\
\text { Tinggi }\end{array}$} \\
\hline L2 & 0.844 & & 0,000 & Valid & & \\
\hline L3 & 0,725 & & 0,000 & Valid & & \\
\hline L4 & 0,724 & & 0,000 & Valid & & \\
\hline L5 & 0,447 & & 0,013 & Valid & & \\
\hline P1 & 0,715 & & 0,000 & Valid & \multirow[t]{5}{*}{0,812} & \multirow{5}{*}{$\begin{array}{l}\text { Reliabilitas } \\
\text { Tinggi }\end{array}$} \\
\hline P2 & 0,795 & & 0,000 & Valid & & \\
\hline P3 & 0,617 & & 0,000 & Valid & & \\
\hline P4 & 0,774 & & 0,000 & Valid & & \\
\hline P5 & 0,699 & & 0,000 & Valid & & \\
\hline
\end{tabular}

Sumber: Data primer diolah 
Berdasarkan tabel 1 dapat diketahui bahwa seluruh item pertanyaan memiliki nilai $r$ hitung yang lebih besar dari $r$ tabel. Nilai signifikansinya juga kurang dari 0,05 . Sehingga dapat disimpulkan bahwa seluruh item pertanyaan kuesioner dapat dinyatakan valid. Uji reliabilitas pada seluruh item variabel bebas masing-masing memiliki nilai alpha sebesar 0,529 untuk variabel uang saku yang termasuk reliabilitas moderat, 0,732 untuk variabel gaya hidup yang termasuk reliabilitas tinggi, 0,758 untuk variabel literasi ekonomi yang termasuk reliabilitas tinggi, dan 0,812 untuk variabel pola konsumsi yang termasuk reliabilitas tinggi. Untuk tahap selanjutnya yakni pengujian asumsi klasik.

Tabel 2 Hasil Uji Asumsi Klasik

\begin{tabular}{|c|c|c|c|c|}
\hline \multirow[t]{2}{*}{ Variabel } & Uji Normalitas & $\begin{array}{l}\text { Uji } \\
\text { Autokorelasi }\end{array}$ & $\begin{array}{l}\text { Uji } \\
\text { Multiolinearitas }\end{array}$ & $\begin{array}{l}\text { Uji } \\
\text { Heterokedastisitas }\end{array}$ \\
\hline & $\begin{array}{l}\text { Kolmogrov- } \\
\text { Smirnov }\end{array}$ & $\begin{array}{l}\text { Durbin } \\
\text { Watson }\end{array}$ & VIF & Uji Glejser \\
\hline Uang Saku & 0,200 & 2,152 & 1,267 & 0,439 \\
\hline Gaya Hidup & & & 1,264 & 0,272 \\
\hline Literasi Ekonomi & & & 1,020 & 0,094 \\
\hline Dummy Fakultas & & & 1,031 & 0,446 \\
\hline
\end{tabular}

Sumber: Data primer diolah

Berdasarkan tabel 2 di atas dapat diketahui bahwasannya nilai signifikansi uji normalitas menggunakan kolmogrov-smirnov sebesar 0,200. Sebuah data dapat dikatakan berdistribusi normal ketika nilai signifikansinya lebih dari 0,05 . Hasil uji normalitas pada penelitian ini 0,200 >0,05 sehingga dapat disimpulkan data ini lolos uji normalitas.

Uji autokorelasi dilakukan pada penelitian ini untuk mengetahui ada atau tidaknya korelasi yang terjadi antara residual pada suatu pengamatan dengan pengamatan lain pada model regresi. Data dapat dikatakan lolos autokorelasi ketika nilai durbin watson berada diantara nilai dU dan 4-dU. Dari tabel statistik durbin watson nilai dU=1,758 dan nilai 4-DU $=2,242$. Berdasarkan tabel 2 nilai durbin watson sebesar 2,152. Sehingga dapat disimpulkan bahwa tidak terdapat autokorelasi pada penelitian ini, karena (dU) $1,758<$ (dw) $2,151<2,242(4-d U)$.

Uji multikolinearitas dilakukan pada penelitian ini untuk melihat apakah terjadi korelasi yang tinggi antara variabel-variabel bebas dalam suatu model regresi linear. Dasar keputusan apakah terjadi multikolinearitas atau tidak adalah jika nilai VIF $<10$ maka tidak terjadi multikolinearitas, dan jika nilai VIF > 10 maka terjadi multikolinearitas. Berdasarkan tabel 2 di atas dapat diketahui seluruh variabel bebas nilai VIFnya kurang dari 10, maka dapat disimpulkan tidak terjadi multikolinearitas pada model regresi penelitian ini.

Uji heterokedastisitas dilakukan pada penelitian ini untuk mengetahui apakah terdapat ketidaksamaan varians dari residual satu ke pengamatan lain. Ketentuannya yaitu jika nilai signifikansi lebih dari 0,05 (sig > 0,05) maka tidak terjadi heterokedastisitas. Sebaliknya jika nilai signifikansi kurang dari 0,05 (sig < 0,05) maka terjadi heterokedastisitas. Berdasarkan hasil uji heterokedastisitas yang terdapat pada tabel 2 dapat diketahui bahwa nilai signifikansi dari uang saku yaitu $(0,439>0,05)$, nilai 
signifikansi gaya hidup yaitu $(0,272>0,05)$, nilai signifikansi literasi ekonomi yaitu $(0,094$ $>0,05)$, dan nilai signifikansi dummy fakultas yaitu $(0,446>0,05)$. Maka dapat disimpulkan jika seluruh variabel tidak terjadi heterokedastisitas. Setelah memastikan beberapa pengujian telah dilakukan, maka perlu melanjutkan ke pengujian utama, yakni regresi.

Tabel 3 Hasil Uji Hipotesis dan Analisis Regresi Linear Berganda

\begin{tabular}{lllll}
\hline Variabel & Beta & t Hitung & Sig. & Kesimpulan \\
\hline Uang Saku & 0,214 & 2,150 & 0,034 & Signifikan \\
Gaya Hidup & 0,100 & 1,009 & 0,316 & Tidak Signifikan \\
Literasi Ekonomi & 0,389 & 4,355 & 0,000 & Signifkan \\
Dummy Fakultas & 0,121 & 1,347 & 0,181 & Tidak Signifikan \\
F hitung & 8,221 & & & \\
Sig F & 0,000 & & & \\
$\begin{array}{l}\text { Adjusted R Square } \\
\text { Pola Konsumsi }\end{array}$ & 0,226 & & \\
UMY & Dahasiswa & & & \\
\hline
\end{tabular}

Sumber: Data primer diolah

Berdasarkan hasil analisis regresi linier berganda pada tabel 3 maka diperoleh persamaan regresi linier berganda sebagai berikut:

$$
Y=0,214 X_{1}+0,100 X_{2}+0,389 X_{3}+0,121 D_{1}+e
$$

Di mana $Y$ adalah Pola Konsumsi Mahasiswa UMY; $X_{1}$ adalah Uang Saku: $X_{2}$ adalah gaya hidup; $X_{3}$ adalah literasi ekonomi; $D_{1}$ adalah dummy fakultas.

Berdasarkan hasil uji F pada tabel 3 dapat diketahui bahwasannya nilai signifikansi yaitu 0,000 yang artinya nilai signifikansi kurang dari $0,05(0,000<0,05)$. Maka dapat disimpulkan bahwa secara simultan variabel independen uang saku, gaya hidup, literasi ekonmi, dan dummy fakultas mempengaruhi variabel dependen pola konsumsi mahasiswa UMY.

Berdasarkan hasil uji t pada tabel 3 dapat diketahui bahwa nilai signifikansi uang saku sebesar 0,034 < 0,05. Dan diperoleh nilai (t hitung) 2,150>1,984 (t tabel). Maka dapat disimpulkan variabel uang saku memiliki pengaruh terhadap variabel pola konsumsi mahasiswa UMY. Sedangkan, dengan nilai signifikansi sebesar 0,316>0,05. Dapat dilihat juga jika nilai (t hitung) 1,009 $<1,984$ ( $t$ tabel). Maka dapat disimpulkan bahwa variabel gaya hidup tidak memiliki pengaruh terhadap variabel pola konsumsi mahasiswa UMY. Penelitian ini juga sejalan dengan penelitian yang dilakukan oleh Damayanti (2017), ia menyimpulkan bahwa uang saku berpengaruh positif dan signifikan terhadap konsumsi mahasiswa di Universitas Muhammadiyah Yogyakarta.

Berdasarkan hasil uji t pada tabel 3 dapat dilihat bahwa nilai signifikansi literasi ekonomi sebesar 0,000 < 0,05. Dapat diperoleh juga nila (t hitung) 4,355 > 1,984 (t tabel). Sehingga dapat disimpulkan bahwasannya variabel literasi ekonomi memiliki pengaruh terhadap variabel pola konsumsi mahasiswa UMY. Penelitian ini tidak sejalan dengan 


\section{Sugiarti \& Setiartiti}

Analisis Determinasi Pola Konsumsi Mahasiswa Universitas Muhammadiyah Yogyakarta

penelitian yang dilakukan Indrianawati dan Soesatyo (2015), penelitiannya menunjukkan bahwa variabel pengetahuan ekonomi berpengaruh secara negatif signifikan terhadap tingkat konsumsi Mahasiswa Pascasarjana Universitas Negeri Surabaya.

Untuk variabel dummy, dengan nilai signifikansi sebesar 0,181 >0,05. Dan diperoleh nilai (t hitung) 1,347 < 1,984 (t tabel). Sehingga dapat disimpulkan bahwa variabel dummy fakultas tidak memiliki pengaruh terhadap variabel pola konsumsi mahasiswa UMY.

Berdasarkan hasil uji koefisien determinasi pada tabel 3 diperoleh nilai Adjusted $\mathrm{R}$ Square sebesar 0,226 . Sehingga dapat diartikan bahwasannya variabel independen yaitu uang saku, gaya hidup, literasi ekonomi, dan dummy fakultas dapat menjelaskan variabel dependen yaitu pola konsumsi mahasiswa UMY sebesar 22,6\% sedangkan sisanya $77,4 \%$ dijelaskan oleh faktor lain di luar model.

\section{Kesimpulan}

Berdasarkan hasil dari penelitian dan pembahasan yang telah penulis jabarkan, terdapat beberapa kesimpulan sebagai berikut: variabel uang saku dan literasi ekonomi berpengaruh secara positif dan signifikan terhadap Pola Konsumsi Mahasiswa Universitas Muhammadiyah Yogyakarta. Sedangkan, Gaya Hidup dan variabel fakultas tidak memiliki pengaruh terhadap Pola Konsumsi Mahasiswa Universitas Muhammadiyah Yogyakarta.

Berdasarkan penelitian yang telah dilakukan, maka penulis ingin memberikan saran sebagai berikut: Berdasarkan hasil penelitian, rata-rata mahasiswa universitas muhammadiyah yogyakarta melakukan pengelolaan uang sakunya, oleh karena itu penulis menyarankan untuk mempertahankan kebiasaan tersebut. Diharapkan mahasiswa juga dapat mengatur pola konsumsinya denga baik dan mendahulukan kebutuhan primer.

Untuk peneliti yang akan membahas topik yang sama dengan penelitian ini, penulis menyarankan untuk menambah jumlah sampel agar hasilnya lebih baik. Untuk variabel bebasnya kalau bisa gunakan variabel yang sekiranya dapat menjelaskan variabel terikat secara lebih baik.

\section{Daftar Pustaka}

Ahmed, J., Mughal, M., \& Zarzoso, I. M. (2018). They Earn and Send: We Spend: Consumption Pattern Of Pakistani Migrant Households. International Journal Of Social Economics, 45(7), 1092-1108. Diakses dari https://www.emerald.com/insight/content/doi/10.1108/IJSE-01-2017$\underline{0029 / \mathrm{full} / \mathrm{pdf}}$

Budanti, H. S., Indriayu, M., \& Sabandi, M. (2017). Pengaruh Lingkungan Sosial Dan Gaya Hidup Terhadap Perilaku Konsumsi Mahasiswa Program Studi Pendidikan Ekonomi 


\section{Sugiarti \& Setiartiti}

Analisis Determinasi Pola Konsumsi Mahasiswa Universitas Muhammadiyah Yogyakarta

UNS. Jumal Pendidikan dan Bisnis Ekonomi, 3(2), . https://doi.org/10.20961/bise.v3i2.16446

Damayanti, A. (2017). Faktor-faktor yang Mempengaruhi Pola Konsumsi Mahasiswa Universitas Muhammadiyah Yogyakarta. Skripsi.

Dornbusch, R., Fisher, S., \& Startz, R. (2001). Makroekonomi. New York: McGraw Hill.

Hanum, N. (2017). Analisis Pengaruh Pendapatan Terhadap Perilaku Konsumsi Mahasiswa Universitas Samudra di Kota Langsa. Jurnal Samudra Ekonomika, 1(2), 107-116. https://doi.org/10.1234/jse.v1i2.325

Indrianawati, E., \& Soesatyo, Y. (2015). Pengaruh Tingkat Pendapatan dan Pengetahuan Ekonomi Terhadap Tingkat Konsumsi Mahasiswa Program Pascasarjana Universitas Negeri Surabaya. Jurnal Ekonomi Pendidikan dan Kewirausahaan, 3(1), 214-226. http://dx.doi.org/10.26740/jepk.v3n2.p214-226

Lutfiah, U., S Hadi, Y., \& Rokhmani, L. (2015). Pengaruh Jumlah Uang Saku dan Kontrol Diri Terhadap Pola Konsumsi Mahasaiswa Fakultas Ekonomi Universitas Negeri Malang. JPE, 8(1), 48-56. diakses dari http://journal2.um.ac.id/index.php/jpe/article/view/1637

Mufidah, N. L. (2012). Pola Konsumsi Masyarakat Perkotaan (Studi Deskriptif Pemanfaatan Foodcourt oleh Keluarga). BioKultur, 1(2), 157-178.

Mulyani, S. (2015). Pola Konsumsi Non-Makanan Mahasiswa Program Studi Pendidikan Ekonomi FE UNY. Skripsi.

Sianturi, S. (2018, December 18). Mahasiswa: Peran, Fungsi dan Pengertian Mahasiswa Menurut Para Ahli. Diambil kembali dari Masuk Universitas:

https://www.masukuniversitas.com/mahasiswa/ 